\title{
Management considerations for stroke-like episodes in MELAS with concurrent COVID-19 infection
}

\author{
Kuntal Sen ${ }^{1,2}$ - Dana Harrar ${ }^{1,3} \cdot$ Andrea Hahn $^{4} \cdot$ Elizabeth M. Wells ${ }^{1} \cdot$ Andrea L. Gropman ${ }^{1,2}$
}

Received: 22 February 2021 / Revised: 26 March 2021 / Accepted: 28 March 2021 / Published online: 1 April 2021

c) Springer-Verlag GmbH Germany, part of Springer Nature 2021

\begin{abstract}
There have been considerations since the beginning of the Coronavirus pandemic that COVID-19 infection, like any other viral illness, can trigger neurological and metabolic decompensation in patients with mitochondrial diseases. At the time of writing, there were no published reports reviewing experiences and guidelines about management of COVID-19 infection in this patient population. We present a challenging case of an adult patient with a known diagnosis of Mitochondrial Encephalomyopathy, Lactic Acidosis and Stroke-like Episodes (MELAS) complicated by COVID-19 infection. She initially presented with altered mental status and vomiting and went on to develop a stroke-like episode, pancreatitis, and pneumatosis intestinalis. We review salient features of her hospitalization, including initiation of thromboprophylaxis in relation to intravenous arginine therapy, caution regarding medications such as remdesivir, and the incidence of gastrointestinal complications.
\end{abstract}

Keywords MELAS · Stroke-like episodes · COVID-19 · Arginine

\section{Introduction}

Management of stroke-like episodes and metabolic decompensation in Mitochondrial Encephalomyopathy, Lactic Acidosis and Stroke-like Episodes (MELAS) with concurrent COVID-19 infection presents a unique set of challenges. There have been no published case reports or management guidelines regarding COVID-19 infection in adult or pediatric patients with MELAS and other mitochondrial disorders. United Mitochondrial Disease Foundation's Scientific and Medical Advisory Board recently provided some general guidance about the pandemic for the mitochondrial disease patient community [1]. At our institution, we cared for a patient with MELAS who presented with altered mental status and vomiting and was found to have a new stroke-like

Kuntal Sen

ksen2@childrensnational.org

1 Center for Neuroscience and Behavioral Medicine, Children's National Hospital, Washington, DC, USA

2 Division of Neurogenetics and Developmental Pediatrics, Children's National Hospital, Washington, DC, USA

3 Program in Stroke and Critical Care Neurology, Children's National Hospital, Washington, DC, USA

4 Division of Infectious Diseases, Children's National Hospital, Washington, DC, USA episode triggered by COVID-19 infection. Considerations related to her care during this admission are reviewed in this report.

\section{Clinical report}

The patient was a 27-year-old female with a genetically confirmed diagnosis of MELAS and a history of multiple stroke-like episodes, refractory epilepsy, intellectual disability, and gastrointestinal dysmotility. She presented with a 1-week history of non-bilious, non-bloody emesis and inability to tolerate feeds and medications. She complained of severe generalized abdominal pain and had had a single dark colored stool. She had a breakthrough seizure the day prior to presentation and was described by her parents as not at her mental baseline. On physical examination, she was alert but oriented only to place. She had decreased verbal output and was able to follow simple commands with the exception of those required for visual field testing. Her face was symmetric, her speech was non-dysarthric, and her extra-ocular movements were intact. She had generalized weakness (4/5 strength) in proximal and distal muscles of upper and lower extremities and diminished muscle bulk. She had an ataxic gait and an intention tremor involving the upper extremities. At baseline, she could ambulate independently. 
Initial laboratory investigations were significant for lactic acid of $3.6 \mathrm{mmol} / \mathrm{L}$ (range 0-2), amylase of 143 units/L (normal $<115$ ), and lipase of 373 units/L (normal 114-286). Basic metabolic panel, complete blood count, and liver function tests were within normal limits. SARS CoV2 PCR from nasopharyngeal swab was positive, and C-reactive protein was elevated at $8.04 \mathrm{mg} /$ dl (normal $<0.50$ ). Given her history of altered mental status raising concern for stroke-like episode, an urgent brain MRI was obtained which demonstrated a new area of diffusion restriction in the left occipital lobe, consistent with acute metabolic injury (Fig. 1). She was administered intravenous (IV) arginine within $5 \mathrm{~h}$ of onset of encephalopathy for treatment of the stroke-like episode, and this was continued for 2 days [2]. Vital signs, electrolytes, and acid-base status were carefully monitored. She was continued on her home medications, including her anti-seizure medications (levetiracetam, oxcarbazepine, and lamotrigine) and mitochondrial cocktail (levocarnitine, riboflavin, thiamine, and pyridoxine). Electroencephalogram showed mild generalized slowing with left occipital sharp waves. For anti-coagulation prophylaxis against COVID-19-related thrombosis, heparin was initiated on day 3 of admission after completion of L-arginine therapy. The unfractionated heparin level was noted to be therapeutic at 0.13 units $/ \mathrm{ml}$ (range $0.1-0.3$ ). She was then transitioned to subcutaneous enoxaparin $40 \mathrm{mg}$ twice a day which was continued until discharge per institutional protocol. Mental status improved slowly, and she was close to her baseline by day 4 of admission. Abdominal ultrasound did not show any evidence of acute appendicitis. Abdominal X-ray demonstrated elongated and stacked appearance of bowel loops and flocculent gas, concerning for pneumatosis intestinalis. Enteral feeds were initially held and slowly advanced while she received total parenteral nutrition (TPN). From a respiratory perspective, she remained stable and did not require intervention.

\section{Discussion}

Medical management of this case was complex given the lack of experience in treating stroke-like episode in the setting of COVID-19 infection. We followed our institutional protocol for treatment of stroke-like episode in MELAS; however, the concurrent COVID-19 infection posed unprecedented challenges, requiring close coordination between pediatric intensivists, neurogeneticists, hematologists, and infectious disease specialists. The patient was started on IV arginine given clinical features suggestive of stroke-like episode and confirmation of acute metabolic injury on brain MRI. L-arginine is effective in decreasing the severity and frequency of stroke-like symptoms, as well as in alleviating tissue injury in patients with MELAS [2]. Stroke-like episodes are a cardinal symptom of MELAS caused by defective oxidative phosphorylation in cerebral vessels leading to impaired vasodilation. The mechanism of action of L-arginine involves endothelialdependent vascular relaxation due to release of nitric oxide $[3,4]$. It was considered that not only had the patient suffered from a metabolic stroke but was also at risk for a large vessel occlusion, cerebral venous sinus thrombosis, and other complications from hypercoagulability related to COVID-19 infection [5, 6]. Similar to other centers, our institution follows a standardized protocol to initiate escalated-dose thromboprophylaxis in critically ill adult patients with COVID-19 infection [7]. The decision was made to delay initiation of anti-coagulation in this case because concurrent use of heparin and IV arginine posed a theoretical risk for bleeding. As discussed before, IV
Fig. 1 MRI Brain (a T2 FLAIR sequences and $\mathbf{b}$ axial ADC [apparent diffusion coefficient] showing acute metabolic injury in the left occipital lobe in addition to extensive chronic injury typical of MELAS (largest area demarcated between yellow arrows). a There is cortical diffusion restriction and $\mathrm{T} 2$ hyperintensity in the left lateral occipital lobe, extending into the posterior left temporal lobe (demarcated by blue arrows, $\mathbf{b}$ )
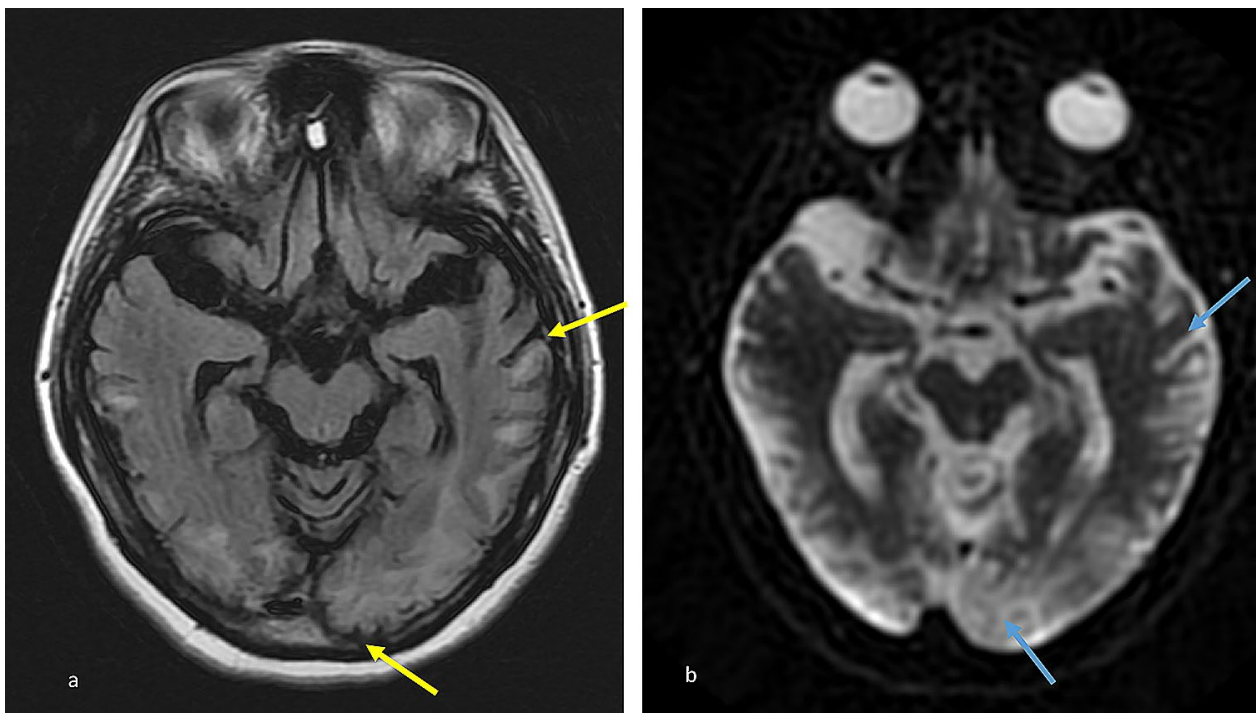
arginine causes vasodilation and systemic hypotension via release of nitric oxide and can have an inhibitory effect on hemostasis $[8,9]$. After the initial bolus, the infusion was continued for 2 days. It was stopped at $48 \mathrm{~h}$ given improved mental status and stable blood lactate levels. The patient began heparin on day 3 of admission after discontinuing IV arginine and subsequently transitioned to subcutaneous enoxaparin. There are no major contraindications to using either anticoagulant in patients with mitochondrial disorders $[10,11]$.

COVID-19 infection should be considered a catabolic stressor like any other infectious illness and can be associated with worsening lactic acidosis in patients with MELAS. Our patient's lactic acid levels were at baseline throughout the hospitalization. We supported her with $125 \%$ of maintenance caloric needs through TPN as a cautionary measure. Metabolic acidosis can worsen work of breathing in patients with COVID-19 pneumonia. Our patient did not have respiratory symptoms and did not require supplemental oxygen. Dexamethasone and/or remdesivir were not considered appropriate, as recent clinical trials and national consensus guidelines support their use only in persons with severe or critical lower respiratory tract disease [12-14]. Additionally, caution should be used when using remdesivir in patients with mitochondrial disorders, especially in those with hepatic dysfunction, as the anti-viral drug can trigger transaminitis [15]. Steroids are typically avoided in patients with mitochondrial disorders as they can promote catabolism and further worsen lactic acidosis [10,11].

Our patient also had severe abdominal pain and distension and was noted to have pneumatosis intestinalis on abdominal X-ray. Hypothetically, this complication-which has been reported before with COVID-19 infection-might be more common in patients with underlying mitochondrial conditions due to pre-existing gastrointestinal motility issues $[16,17]$. Our patient underwent complete bowel rest and was started on TPN. She also had mild elevation in lipase and amylase levels on admission concerning for pancreatitis, which improved throughout the hospital stay. Use of convalescent plasma has been shown to offer clinical benefit, including radiological resolution of lung disease, reduction in viral loads, and improved survival in patients with COVID-19 infection in a limited number of published studies [18]. However, national consensus guidelines did not support its use outside of a clinical trial at the time of treatment for this patient $[13,14]$.

As the departments of health in each state are determining vaccination strategies for adults with co-morbid conditions, patients with mitochondrial disorders (such as MELAS, Kearns-Sayre syndrome, Leber's Hereditary Optic Neuropathy, etc.) should be given priority due to risk for severe disease [19]. Our hospital is in the process of identifying vulnerable patients based on ICD-10 codes. We are including patients with mitochondrial diseases including MELAS as tier 1 in our priority list.

\section{Conclusion}

This is the first report of COVID-19 infection in a patient with MELAS complicated by stroke-like episode, pneumatosis intestinalis, and pancreatitis. We identified several considerations that impact the treatment of stroke-like episodes/metabolic decompensation with concurrent COVID19 infection.

\section{Declarations}

Conflict of interest The authors have no conflict of interest.

\section{References}

1. COVID-19 Recommendations from UMDF's Scientific and Medical Advisory Board (SMAB) Chairman, Dr. Bruce Cohen. https:// www.umdf.org/coronavirus/9482-2/. Accessed 18 Feb 2021

2. Koenig MK, Emrick L, Karaa A, Korson M, Scaglia F, Parikh S, Goldstein A (2016) Recommendations for the management of strokelike episodes in patients with mitochondrial encephalomyopathy, lactic acidosis, and strokelike episodes. JAMA Neurol 73(5):591-594

3. Koga Y, Akita Y, Junko N, Yatsuga S, Povalko N, Fukiyama R, Ishii M, Matsuishi T (2006) Endothelial dysfunction in MELAS improved by 1-arginine supplementation. Neurology 66(11):1766-1769

4. Koga Y, Akita Y, Nishioka J, Yatsuga S, Povalko N, Tanabe Y, Fujimoto S, Matsuishi T (2005) L-arginine improves the symptoms of strokelike episodes in MELAS. Neurology 64(4):710-712

5. Hess DC, Eldahshan W, Rutkowski E (2020) COVID-19-related stroke. Transl Stroke Res 11(3):322-325

6. Beyrouti R, Adams ME, Benjamin L, Cohen H, Farmer SF, Goh YY, Humphries F, Jäger HR, Losseff NA, Perry RJ, Shah S, Simister RJ, Turner D, Chandratheva A, Werring DJ (2020) Characteristics of ischaemic stroke associated with COVID-19. J Neurol Neurosurg Psychiatry 91(8):889-891

7. Chowdhury JF, Moores LK, Connors JM (2020) Anticoagulation in hospitalized patients with Covid-19. N Engl J Med 383(17):1675-1678

8. Stief TW, Weippert M, Kretschmer V, Renz H (2001) Arginine inhibits hemostasis activation. Thromb Res 104(4):265-274

9. Lyapina LA, Obergan TY, Pastorova VE (2009) Anticoagulant effects of a complex of high molecular weight heparin and arginine. Bull Exp Biol Med 147(3):328-330

10. Parikh S, Saneto R, Falk MJ, Anselm I, Cohen BH, Haas R, Medicine Society TM (2009) A modern approach to the treatment of mitochondrial disease. Curr Treat Options Neurol. 11(6):414-430

11. Parikh S, Goldstein A, Karaa A, Koenig MK, Anselm I, BrunelGuitton C, Christodoulou J, Cohen BH, Dimmock D, Enns GM, Falk MJ, Feigenbaum A, Frye RE, Ganesh J, Griesemer D, Haas R, Horvath R, Korson M, Kruer MC, Mancuso M, McCormack S, Raboisson MJ, Reimschisel T, Salvarinova R, Saneto RP, Scaglia F, Shoffner J, Stacpoole PW, Sue CM, Tarnopolsky M, Van Karnebeek C, Wolfe LA, Cunningham ZZ, Rahman S, Chinnery PF (2017) Patient care standards for primary mitochondrial 
disease: a consensus statement from the Mitochondrial Medicine Society. Genet Med. https://doi.org/10.1038/gim.2017.107

12. Beigel JH, Tomashek KM, Dodd LE, Mehta AK, Zingman BS, Kalil AC, Hohmann E, Chu HY, Luetkemeyer A, Kline S, de Castilla LD, Finberg RW, Dierberg K, Tapson V, Hsieh L, Patterson TF, Paredes R, Sweeney DA, Short WR, Touloumi G, Lye DC, Ohmagari N, Oh MD, Ruiz-Palacios GM, Benfield T, Fätkenheuer G, Kortepeter MG, Atmar RL, Creech CB, Lundgren J, Babiker AG, Pett S, Neaton JD, Burgess TH, Bonnett T, Green M, Makowski M, Osinusi A, Nayak S, Lane HC, ACTT-1 Study Group Members (2020) Remdesivir for the treatment of covid19—final report. N Engl J Med. 383(19):1813-1826

13. Alhazzani W, Evans L, Alshamsi F, Møller MH, Ostermann M, Prescott HC, Arabi YM, Loeb M, Ng Gong M, Fan E, Oczkowski S, Levy MM, Derde L, Dzierba A, Du B, Machado F, Wunsch H, Crowther M, Cecconi M, Koh Y, Burry L, Chertow DS, Szczeklik W, Belley-Cote E, Greco M, Bala M, Zarychanski R, Kesecioglu J, McGeer A, Mermel L, Mammen MJ, Nainan Myatra S, Arrington A, Kleinpell R, Citerio G, Lewis K, Bridges E, Memish ZA, Hammond N, Hayden FG, Alshahrani M, Al Duhailib Z, Martin GS, Kaplan LJ, Coopersmith CM, Antonelli M, Rhodes A (2021) Surviving Sepsis Campaign Guidelines on the Management of Adults With Coronavirus Disease 2019 (COVID-19) in the ICU: First Update. Crit Care Med 49(3):e219-e234
14. IDSA Guidelines: https://www.idsociety.org/practice-guideline/ covid-19-guideline-treatment-and-management/. Accessed $18 \mathrm{Feb}$ 2021

15. Zampino R, Mele F, Florio LL, Bertolino L, Andini R, Galdo M, De Rosa R, Corcione A, Durante-Mangoni E (2020) Liver injury in remdesivir-treated COVID-19 patients. Hepatol Int 14(5):881-883

16. Bhayana R, Som A, Li MD, Carey DE, Anderson MA, Blake MA, Catalano O, Gee MS, Hahn PF, Harisinghani M, Kilcoyne A, Lee SI, Mojtahed A, Pandharipande PV, Pierce TT, Rosman DA, Saini S, Samir AE, Simeone JF, Gervais DA, Velmahos G, Misdraji J, Kambadakone A (2020) Abdominal imaging findings in COVID19: preliminary observations. Radiology 297(1):E207-E215

17. Wong K, Kim DH, Khanijo S, Melamud A, Zaidi G (2020) Pneumatosis intestinalis in COVID-19: case series. Cureus 12(10):e10991

18. Rajendran K, Krishnasamy N, Rangarajan J, Rathinam J, Natarajan M, Ramachandran A (2020) Convalescent plasma transfusion for the treatment of COVID-19: systematic review. J Med Virol 92(9):1475-1483. https://doi.org/10.1002/jmv.25961

19. Letter to State Health Officials Regarding Vaccine Access for Patients with Mitochondrial Disease and metabolic disorders. https://www.umdf.org/coronavirus/ars-cov-2-covid-19-covid-19vaccines-and-mitochondrial-disease-2/. Accessed 18 Feb 2021 